\title{
Translation, adaptation and validation of the Bulgarian version of the King's Parkinson's Disease Pain Scale
}

\author{
Galina Stoyanova-Piroth ${ }^{1 *}$, Ivan Milanov ${ }^{1}$ and Katerina Stambolieva ${ }^{2}$
}

\begin{abstract}
Background: The purpose of the present study was to translate and cross-culturally adapt the King's Parkinson's Disease Pain Scale (KPPS) into Bulgarian and to investigate its psychometric properties in order to provide a validated Parkinson's disease-specific pain instrument in Bulgarian language (KPPS-BG).

Methods: Translation into Bulgarian and a cultural adaptation were performed to obtain KPPS-BG. A total of 162 patients with idiopathic Parkinson's disease were screened for pain using the complementary to the KPPS questionnaire - King's Parkinson's Disease Pain Questionnaire (KPPQ). KPPS-BG domain and total scores were calculated and internal consistency, construct validity and test-retest reliability were examined for 129 patients having one or more positive items in the KPPQ-BG.
\end{abstract}

Results: $79.6 \%$ of the patients reported one or more types of pain. The most common type was musculoskeletal pain $(83.7 \%)$, followed by nocturnal pain $(55.0 \%)$, fluctuation-related pain $(50.1 \%)$, radicular pain (43.4\%), chronic pain (31.0\%), discoloration, edema/swelling (27.1\%) and, oro-facial pain (14.3\%). Mean KPPS-BG total score was $21.1 \pm 17.3$ SD. KPPS-BG showed a good reliability (Cronbach's alpha 0.75 ). The test-retest reliability of the KPPS-BG was high and the intraclass correlation coefficient was 0.92, demonstrating a good repeatability. KPPS-BG total score was higher in patients with postural instability gait difficulty motor subtype, compared to tremor-dominant or indeterminate subtype. Significant positive correlations were found between KPPS-BG total score and modified H\&Y, Movement Disorders Society Unified Parkinson's Disease Rating Scale part III.

Conclusions: The KPPS-BG constitutes a reliable, comprehensive and useful tool for pain assessment in native Bulgarian patients with Parkinson's disease.

Keywords: Parkinson's Disease, Pain, KPPS, Cross-cultural adaptation

\section{Background}

Pain has been reported as symptom of Parkinson's disease (PD) since the first description of the disorder [1]. In recent years pain is increasingly recognized as important feature of the disease [2] and a cause of reduced quality of life (QoL) [3, 4]. But despite being one of the

\footnotetext{
* Correspondence: dr.gstoyanova@gmail.com

${ }^{1}$ St. Naum Hospital of Neurology and Psychiatry, Medical University, 1, Louben Roussev str., 1113 Sofia, Bulgaria

Full list of author information is available at the end of the article
}

most troublesome non-motor symptoms (NMS) in patients with both early and advanced PD [5] and, the most frequently reported presenting NMS [6], pain is still under-diagnosed and under-treated [7].

Based on the assessment using general, non-PD specific tools, pain is estimated to occurs in up to $85 \%$ of the patients with PD [7]. This makes pain in PD patients 2-3 times more frequent compared to age-matched healthy individuals [8]. Pains in PD were classified as related or unrelated to the disease [9]. Based on aetiology,

(c) The Author(s). 2021 Open Access This article is licensed under a Creative Commons Attribution 4.0 International License, which permits use, sharing, adaptation, distribution and reproduction in any medium or format, as long as you give appropriate credit to the original author(s) and the source, provide a link to the Creative Commons licence, and indicate if changes were made. The images or other third party material in this article are included in the article's Creative Commons licence, unless indicated otherwise in a credit line to the material. If material is not included in the article's Creative Commons licence and your intended use is not permitted by statutory regulation or exceeds the permitted use, you will need to obtain permission directly from the copyright holder. To view a copy of this licence, visit http://creativecommons.org/licenses/by/4.0/ The Creative Commons Public Domain Dedication waiver (http://creativecommons.org/publicdomain/zero/1.0/) applies to the data made available in this article, unless otherwise stated in a credit line to the data. 
Ford [10] classifies pain in PD into five categories: musculoskeletal pain, neuropathic radicular pain, dystoniarelated pain, akathisia and primary central parkinsonian pain. Pain can be also categorised as nociceptive, neuropathic and miscellaneous [11].

Until recently, there was no specific validated diagnostic tool for detecting pain in PD. Different specific and non-specific pain scales were used that have not been adopted to and validated for PD patients $[9,12,13]$. This leads to a methodological deficiency for consensual interpretation of the results.

Chaudhuri et al. [14] have created and validated the first specific PD pain scale, named "King's Parkinson's disease Pain Scale" - KPPS. Its seven domains include 14 items. KPPS has already been used as a reliable tool available in English language to assess various types of PD-pain $[4,15-17]$ and as a secondary outcome in two international multicenter, randomized, controlled trials $[18,19]$. More recently, the effect of other therapeutic strategies on pain in PD was also assessed by KPPS [20]. Available is an officially translated version in German [21]. Recently, a validated version in Turkish, Hindi and Persian were published [22-24].

The clinical assessment of pain in PD patients in Bulgaria is usually underperformed. Questionnaires or studies on the reliability and validity of instruments assessing pain in patients with Parkinson`s disease in the Bulgarian language do not exist. The aim of the present study is translation, adaptation and validation of the King's Parkinson's Disease Pain Scale in Bulgarian language (KPPS-BG) in order to use it as a reliable instrument intended for clinical monitoring the pain in Bulgarian patients with PD.

\section{Methods}

Participants were recruited from the Department of Movement Disorders of the University Hospital for Active Treatment in Neurology and Psychiatry, "St Naum" Sofia, Bulgaria. All inpatient and outpatient treated during the study period were screened for eligibility. Assessment was done by a senior neurologist, specialized in movement disorders.

In the study were enrolled 162 patients aged 18 years or more with diagnosed idiopathic PD based on the UK Parkinson's Disease Society Brain Bank criteria [25]. All subjects were tested for PD-related pain. The exclusion criteria were: (1) patients with atypical or secondary Parkinsonism; (2) patients with comorbidities causing pain, such as severe osteoarthritis, neuropathy, malignancy, rheumatic diseases or other chronic pain conditions; (3) Mini-Mental State Examination (MMSE) score <24 [26], indicating significant cognitive impairment, that potentially interferes with the ability to understand the content of the questions.
Demographic and clinical data were collected upon the first visit. All patients were assessed by using the modified Hoehn and Yahr (H\&Y) scale for rating the stage of a patient's disease progression [27] and the Movement Disorders Society Unified Parkinson's Disease Rating Scale (MDS-UPDRS) part III (motor examination) [28] in on state. The motor subtype was determined based on particular items of the MDSUPDRS. [29]. Levodopa equivalent daily dose (LEDD) was calculated for each patient according to Tomlinson et al. [30].

All patients gave written informed consents prior to participation, approved by the Ethics Committee of the University Hospital for Active Treatment in Neurology and Psychiatry "St Naum", Sofia. The study was conducted in accordance with the ethical standards set forth on the Declaration of Helsinki. The participants were free to withdraw from the study at any time.

Following a permission granted by the authors and according to their requirements the original English versions of the KPPS (along with it the proposed King's Parkinson's Disease Pain Questionnaire-KPPQ) [31] were translated into Bulgarian language independently by two bilingual persons with medical education. After discussion held among the translators some items of the Bulgarian version of KPPQ and KPPS (KPPQ-BG and KPPS-BG) were edited according to the rules of the Bulgarian language for semantic and grammatical accuracy. By means of a consensus a prefinal version of KPPQ-BG and KPPS-BG were obtained. Two licensed translators unaware of the original version of the KPPQ and KPPS performed independently back translation from Bulgarian to English of KPPQ-BG and KPPS-BG. No significant differences between the translation and retrotranslation were found.

Ten patients with various age and educational levels were tested with the pre-final questionnaire and scale (KPPQ-BG and KPPS-BG). They were invited to verbally evaluate the clarity of the content of the items and their comprehensibility. Patients have been filling KPPQ-BG in the presence of a medical specialist, who was helping them out where needed. After filling the questionnaire the patients give answers concerning the severity and frequency of the available pain. The medical specialist calculates the score of each domain and the total score of KPPS-BG.

The following language adaptations were performed: "around their joints" was replaced by "around the joints", "around the liver, stomach or bowels" was replaced by "in the area of the liver, stomach or bowels" and "aching pain" was replaced by "pain".

Patients declared that they have not encountered difficulties in completing the questionnaire with the help from the relevant specialist, granted upon such need a 
request and in answering the questions on the raterinterview-based scale.

The back-translated version of the questionnaire and scale were discussed with the authors of the KPPQ and KPPS. After some amendments the final versions KPPQ-BG and KPPS-BG were again back-translated and approved by the authors for validation and for use in Bulgarian PD patients.

The KPPS-BG consist of the same 14 items as KPPQBG, which are distributed into seven domains as follow: (1) Musculoskeletal pain (1 item); (2) Chronic pain (2 items); (3) Fluctuation-related pain (3 items); (4) Nocturnal pain (2 items); (5) Oro-facial pain (3 items); (6) Discoloration, oedema/swelling (2 items); (7) Radicular pain (1 item). Patients need to rank the described sense of pain for each item by the severity in a 4-point Likert scale ( 0 , none to 3 , severe) and frequency in a 5-point Likert scale ( 0 , never to 4 , very frequently). The range of possible KPPS-BG total scores is from 0 to 168 . Higher score values indicate higher levels of pain.

In total 162 patients with PD were tested with KPPQBG. Face-to-face clinical interview was conducted comprising two steps. In the first one, all patients had to fill the KPPQ-BG, answering "Yes" or "No" for all 14 items. Only patients with 1 or more positive answers were evaluated by KPPS-BG. The KPPS-BG domain and total scores were calculated for 129 patients. 43 randomly selected patients were interviewed again after two weeks to evaluate test-retest reliability [32].

\section{Statistical analysis}

Descriptive statistics were used for calculating the mean scores of the KPPS-BG and sociodemographic and clinical data. Item discrimination was evaluated using itemto-total score correlation that is criteria for discarding items. The item-to-total score correlation of 0.20 has been given as the cut-off point below which items can be discarded [33]. Therefore, only the items that met the correlation greater than 0.20 were retained. The internal consistency of KPPS-BG was determined by estimating Cronbach's $\alpha$ coefficient and item-total correlation (Spearman's rank correlation $<0.25$ was considered to be weak, while values equal to or greater than 0.76 were considered to indicate a strong relationship). In general, Internal consistency refers to the extent to which all of the items within a scale measure the different aspects of the same attribute. Cronbach's alpha is often used in assessing the reliability, where Cronbach's $\alpha>0.7$ (Nunnally's criterion) is considered as sufficiently reliable [34].

The test-retest reliability was evaluated by calculating the intraclass correlation coefficient (ICC) using the two-way mixed effect models according to classification of Shrout and Fleiss (1979) [35]. The reliability was evaluated by classification proposed by Slick (2006) as following: Very high ICCs $\geq 0.90$, high ICCs $=0.80-0.89$, adequate $\mathrm{ICCs}=0.70-0.79$, marginal $\mathrm{ICCs}=0.60-0.69$ and low ICCs $<0.60$ [36]. The convergent construct validity was tested with estimation of the correlation of the KPPS-BG total score with other instruments that express PD stage and severity as modified H\&Y stage and MDSUPDRS III. The discriminant validity was established by evaluation of a difference between the KPPS-BG scores and clinical parameters, using Kruskal-Wallis ANOVA.

The analyses were performed using the computer software Statistica 8.0 for Windows (Stat Soft Inc. USA).

\section{Results}

Mean age of participants in the investigation was $65.4 \pm$ 8.4 (range $40-80$ years). There were only few participants younger than 50 years $(4.7 \%)$. The majority of the PD patients were within the age range of $50-70$ years $(63.5 \%)$. Both sexes were equally represented. The mean duration of the disease was $6.6 \pm 5.7$ years. Sixty-three patients $(48.8 \%)$ reported disease durations of 6-10 years and $22(17 \%)$ of over 10 years. Twenty-three patients $(17,8 \%)$ were newly diagnosed and drug naive. Sociodemographic and clinical characteristic of patients with KPPS-BG score $>0$ are presented in Table 1 .

All 129 patients with symptoms of pain over the last month completed KPPQ-BG manually. Based on the patients' answers, pain severity and frequency were quantitatively measured and the KPPS-BG score was calculated. Missing information on any of the items was not observed (analysis of missing data not supplied). Eight of the patients $(6.2 \%)$ had ambiguities related to the words "abnormal" and "involuntary" in question number 5 of the KPPQ-BG and additionally explanations were provided by the interviewing medical specialist. In some cases, additional explanations were required for other items.

There were no significant differences between the distribution of the positive responses of the Bulgarian and mixed British and Romanian populations using English version of KPPS, for most of the questions. Only in item 4 and domain 4 the responses of the Bulgarian patients were significantly different (Table 2).

Internal consistency was calculated using Cronbach's alpha coefficient, based on the data obtained from the first examination $(n=129)$. The value of Cronbach's alpha for the total scale KPPS-BG was 0.75, which showed good internal reliability. The item-total correlations were 0.21 or greater for 13 items, ranged from 0.21 (item 3) to 0.72 (item 14). The item 12: "Burning sensation in the mouth" have values of item-total correlations $<0.20$, which defines it as poorly informative and gives reason to exclude it from the subsequent analysis (Table 3). 
Table 1 Sociodemographic and clinical characteristic of patients with PD and pain $(n=129)$

\begin{tabular}{|c|c|}
\hline Variable & Values \\
\hline \multicolumn{2}{|l|}{ Sex, n (\%) } \\
\hline Male & $65(50.4)$ \\
\hline Female & $64(49.6)$ \\
\hline Age, years (mean $\pm S D$ ) & $65.4 \pm 8.4$ \\
\hline \multicolumn{2}{|l|}{ Education, n (\%) } \\
\hline primary school & $6(4.7)$ \\
\hline secondary school & $88(68.2)$ \\
\hline university & $35(27.1)$ \\
\hline \multicolumn{2}{|l|}{ Marital status, n (\%) } \\
\hline single & $18(14.0)$ \\
\hline married & $84(65.1)$ \\
\hline widowed & $27(20.9)$ \\
\hline Duration of disease, years (mean \pm SD) & $6.6 \pm 5.7$ \\
\hline Mean age of PD onset (years) & $58.7(10.2)$ \\
\hline \multicolumn{2}{|l|}{ Motor subtype, n (\%) } \\
\hline Tremor-dominant (TD) & $59(45.7)$ \\
\hline Postural Instability Gait Disorder (PIGD) & $65(50.4)$ \\
\hline Indeterminate & $5(3.9)$ \\
\hline Modified H\&Y stage, median (range) & $2.0(1-4)$ \\
\hline MDS-UPDRS III & $31.4 \pm 11.1$ \\
\hline LEDD, mg (mean \pm SD) & $621.9 \pm 500.1$ \\
\hline Range & (0-1775 mg) \\
\hline
\end{tabular}

SD standard deviation; PD Parkinson's Disease; MDS-UPDRS III Movement Disorders Society Unified Parkinson's Disease Rating Scale part III (motor examination); LEDD Levodopa Equivalent Daily Dose

The test-retest reliability of the KPPS-BG was high and the intraclass correlation coefficient (ICC) was 0.92 (confidence interval $(\mathrm{CI})=0.82-0.98)$. All items showed high positive correlations between the first and second exam (range from 0.78 to 0.98 ), which exceeded the recommended value of 0.75 (Nunnally) and show that items contained in the KPPS-BG had a good repeatability (Table 3).

Convergent validity of the domains and total scores of the KPPS-BG with other instruments that assess disability status of PD patients was estimated using Spearman's rank correlation coefficients $\left(r_{s}\right)$ (Table 4). The mean scores of domains and total score of the KPPS-BG are presented in Table 4.

Figure 1 shows a scatterplot with the positive correlation between KPPS-BG Score and modified H\&Y (A) and MDS-UPDRS III (B).

Discriminate construct validity was tested by difference between KPPS-BG total score and motor subtype of PD using Kruskal-Wallis ANOVA with three levels (Tremordominant (TD), Postural Instability Gait Disorder (PIGD) and Indeterminate). There was a significant effect of the
PD motor subtype on the KPPS-BG total score (H (2, $129)=26.26, p<0.001$ ). A post hoc Mann-Whitney U-test showed significant difference of KPPS-BG total scores between patients with TD subtype vs. PIGD $(p<0.001)$ only. The mean score of TD was $13.5 \pm 2.5$, median 7 , for PIGD was $28.3 \pm 19.1$, median 23 and Indeterminate subtype$15.4 \pm 7.1$, median 16. That result shows a good discriminative validity of KPPS-BG.

\section{Discussion}

Pain is a subjective, physiological and psychological experience, influenced by sociocultural factors [37]. In the Parkinson population, pain is an important and frequently reported NMS [10]. In order to investigate the types of pain and its frequency in PD for the Bulgarian patients, we translated and validated the only one PDspecific scale for pain- KPPS. The results of the present study demonstrate that KPPS-BG had a good reliability and validity. Cronbach's $\alpha$ of total scale was 0.75 , which indicates a good level of internal consistency similar to those reported in the original publication (0.78) [14], by Rodríguez-Violante et al. (0.74) [15], and by Soyuer et al. (0.827) [22]. Taghizadeh et al. found Cronbach's 0.88 [24].

Almost $80 \%$ of our patients reported one or more types of pain. In a recently published cross-sectional study, the authors reported a pain frequency of $88.6 \%$ [15]. Silverdale et al. [16] also using KPPS in patients with early/moderate PD found $85 \%$ of participants to experience pain. Slightly lower frequency was revealed in Brazilian cohort (70.3\%) [17]. One German study based on a self-developed Parkinson's Disease Pain Questionnaire revealed up to $95 \%$ prevalence of pain in PD patients [38]. Lower prevalence is reported in Indian cohort (52.1\%) [23] although mean disease duration and mean $\mathrm{H} \& \mathrm{Y}$ are similar to ours.

In the present study, the most common type of pain was musculoskeletal (83.7\%), which is in line with the results of some previous studies [17, 23, 31], but higher than others [15]. Independent of the use of a PD specific pain assessment tool, this is the most common type of pain described in the literature (frequency range: 40 $90 \%)[7,11]$.

Significant differences between the Bulgarian and other populations were observed for item 4 and nocturnal pain domain. Pain deep within the body (item 4) refers to the central pain. It has been reported by $12 \%$ of our patients. These results are in line with other studies where this type of pain was estimated to be present in up to $10 \%$ of PD patients [11]. However, they are significantly lower than the results retrieved applying KPPS [23, 31]. Possibly, these differences arise from patient population and sociocultural peculiarities. 
Table 2 Proportion of patients with positive responses of KPPS-BG $(n=129)$ and comparison with the original KPPS $(n=300)$ [31]

\begin{tabular}{|c|c|c|c|}
\hline Items & KPPS-BG & $\begin{array}{l}\text { KPPS } \\
\text { English }\end{array}$ & Fisher exact test \\
\hline 1. Pain around joints (musculoskeletal) & 83.7 & 81.3 & 0.46 \\
\hline 2. Pain related to internal organ & 20.2 & 21.0 & 0.81 \\
\hline 3. Generalised non-specific pain in the stomach area & 13.9 & 17.7 & 0.11 \\
\hline 4. Pain deep within the body & 12.4 & 31.7 & 0.001 \\
\hline 5. Dyskinetic pain & 16.3 & 17.0 & 0.86 \\
\hline 6. Painful muscle cramps in a specific area during "off" period & 41.9 & 32.7 & 0.08 \\
\hline 7. Generalized "off" period pain & 17.8 & 22.3 & 0.29 \\
\hline 8. PLM or RLS-associated pain & 24.8 & 28.0 & 0.49 \\
\hline 9. Pain while turning in bed at night & 47.3 & 47.7 & 0.94 \\
\hline 10. Pain when chewing & 4.7 & 6.7 & 0.43 \\
\hline 11. Pain due to grinding teeth during the night & 5.1 & 5.7 & 0.25 \\
\hline 12. Burning sensation in the mouth & 3.3 & 2.7 & 0.31 \\
\hline 13. Burning pain in the limbs & 18.6 & 18.3 & 0.93 \\
\hline 14. Shooting pain/pins \& needles & 43.4 & 41.7 & 0.74 \\
\hline \multicolumn{4}{|l|}{ Domains } \\
\hline 1. Musculoskeletal pain & 83.7 & 81.3 & 0.46 \\
\hline 2. Chronic pain & 31.0 & 40.0 & 0.08 \\
\hline 3. Fluctuation-related pain & 50.1 & 44.0 & 0.37 \\
\hline 4. Nocturnal pain & 55.0 & 66.0 & 0.03 \\
\hline 5. Oro-facial pain & 14.3 & 13.3 & 0.78 \\
\hline 6. Discoloration, edema/swelling & 27.1 & 30.3 & 0.69 \\
\hline 7. Radicular pain & 43.4 & 41.7 & 0.74 \\
\hline
\end{tabular}

KPPS-BG Bulgarian version of the King's Parkinson's Disease Pain Scale; KPPS King's Parkinson's Disease Pain Scale; PLM periodic limb movements; RLS restless legs syndrome

Table 3 Internal consistency reliability and test-retest reliability (Intraclass correlation coefficients and $95 \%$ confidence intervals) of KPPS-BG

\begin{tabular}{llll}
\hline $\begin{array}{l}\text { Items of } \\
\text { KPPS-BG }\end{array}$ & $\begin{array}{l}\text { Item-total correlations } \\
\text { (IT-TC) (n= 129) }\end{array}$ & Cronbach's a if item deleted & $\begin{array}{l}\text { ICCs (CI) } \\
\text { ( }=\mathbf{4 3} \text { elet }\end{array}$ \\
\hline 1. Pain around joints (musculoskeletal) & 0.46 & 0.75 & $0.84(0.67-0.90)$ \\
2. Pain related to internal organ & 0.31 & 0.72 & $0.78(0.62-0.88)$ \\
3. Generalised non-specific pain in the stomach area & 0.21 & 0.74 & $0.84(0.66-0.89)$ \\
4. Pain deep within the body & 0.38 & 0.75 & $0.97(0.92-0.99)$ \\
5. Dyskinetic pain & 0.68 & 0.73 & $1(1-1)$ \\
6. Painful muscle cramps in a specific area during "off" periods & 0.41 & 0.73 & $0.94(0.85-0.91)$ \\
7. Generalized "off" period pain & 0.49 & 0.79 & $0.85(0.72-0.91)$ \\
8. PLM or RLS-associated pain & 0.52 & 0.77 & $0.97(0.87-0.99)$ \\
9. Pain while turning in bed & 0.71 & 0.73 & $0.95(0.91-0.98)$ \\
10. Pain when chewing & 0.64 & 0.71 & $1(1-1)$ \\
11. Pain due to grinding teeth & 0.46 & 0.75 & $0.98(0.96-0.99)$ \\
12. Burning sensation in the mouth & 0.15 & 0.74 & $0.80(0.61-0.87)$ \\
13. Burning pain in the limbs & 0.66 & 0.73 & $0.98(0.93-0.99)$ \\
14. Shooting pain/pins \& needles & 0.72 & 0.71 & $0.97(0.91-0.99)$
\end{tabular}


Table.4 Domain scores and total score of the KPPS-BG and correlations with other PD specific scales

\begin{tabular}{llllll}
\hline KPPS-BG scores & Mean score (SD) & Median & Range & Modified H\&Y & MDS-UPDRS III \\
\hline 1. Musculoskeletal pain & $5.13(3.59)$ & 6 & $0-12$ & $\mathbf{0 . 2 4 ^ { * }}$ & $\mathbf{0 . 2 6 ^ { * }}$ \\
2. Chronic pain & $1.57(3.13)$ & 0 & $0-18$ & 0.05 & 0.03 \\
3. Fluctuation-related pain & $4.46(6.51)$ & 1 & $0-36$ & $\mathbf{0 . 6 1 ^ { * }}$ & $\mathbf{0 . 5 4 ^ { * }}$ \\
4. Nocturnal pain & $5.35(6.33)$ & 0 & $0-24$ & $\mathbf{0 . 2 7 ^ { * }}$ & 0.2 \\
5. Oro-facial pain & $0.88(3.03)$ & 0 & $0-12$ & $\mathbf{0 . 3 1 *}$ & $\mathbf{0 . 2 4}$ \\
6. Discoloration, edema/swelling & $1.41(2.72)$ & 0 & $0-12$ & 0.13 & 0.11 \\
7. Radicular pain & $2.17(3.28)$ & 0 & $0-12$ & 0.13 & 0.04 \\
Total score & $21.11(17.32)$ & 17 & $1-90$ & $\mathbf{0 . 4 7 *}$ & $\mathbf{0 . 4 2 *}$ \\
\hline
\end{tabular}

* Statistical significance of Spearman correlation coefficient, $p<0.05$; Modified H\&Y, modified Hoehn and Yahr scale; MDS-UPDRS III Movement Disorders Society Unified Parkinson's Disease Rating Scale part III (motor examination); KPPS-BG Bulgarian version of the King's Parkinson's Disease Pain Scale; SD standard deviation

$55.0 \%$ of patients in the present study suffered from nocturnal pain. This domain shows a large variability among different studies $[15,31]$ The third most common type of pain was fluctuation-related pain (50.1\%), followed by radicular pain (43.4\%) and chronic pain (31.0\%). 27.1 and $14.3 \%$ of the patients, respectively, reported discoloration edema/swelling pain and orofacial pain. Likewise, these two pain categories were least common in other studies [15, 23, 31].

The mean scores of all domains of the KPPS-BG were similar to those observed in the original validation [14] except for chronic pain (domain 2) where the patients' score of the original KPPS was significantly higher $(3.37 \pm 5.53)$ in comparison with the score of the Bulgarian population.

The mean total score of KPPS-BG was $21.1 \pm 17.3$ and median 17 , which is within the range of those reported by other authors $[14,15]$. In the recently published Indian validation, the mean total KPPS score was found to be $16.02 \pm 10.57$ [23].
Item 12. Burning sensation in the mouth demonstrated an item-to-total score correlation below 0.20 . Hence, this item was determined as low informative and unreliable for the Bulgarian population.

We have observed a statistical correlation between modified H\&Y stage, MDS-UPDRS III and the total score KPPS-BG (Tabale 4). The observed positive correlations reflect the domination of the musculosceletal, fluctuation-related, nocturnal and orofacial pain in the overall score. Similar data was published [14, 15, 23]. Contrariwise, Silverdale et al. [16] found no correlation between UPDRS III and KPPS most domains. This is probably due to different clinical characteristics: shorter mean disease duration, and UPDRS IV indicated only a low number of PD patients suffering from fluctuations. De Mattos et al. [17] analysed only 38 patients also with shorter mean disease duration and lower UPDRS III score and reported no significant correlation of UPDRS III and KPPS total score.
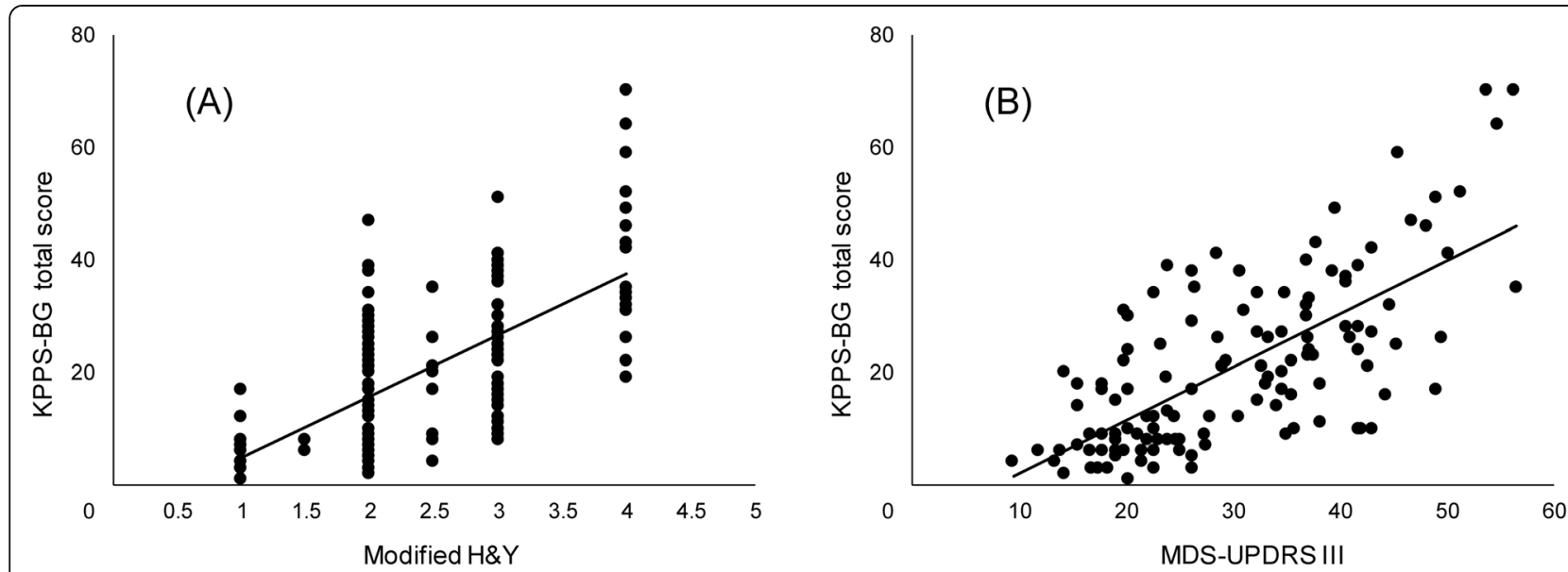

Fig. 1 Scatterplot showing the correlations between KPPS-BG Score and modified H\&Y (A) and MDS-UPDRS III (B). The individual points represent individual cases. KPPS-BG, Bulgarian version of the King's Parkinson's Disease Pain Scale; Modified H\&Y, modified Hoehn and Yahr scale; MDSUPDRS III, Movement Disorders Society Unified Parkinson's Disease Rating Scale part III (motor examination) 
The significant difference of KPPS-BG total scores between patients with various motor subtypes of the disease is published also for the Mexican population [15]. Patients with TD subtype were scored lowest.

KPPS-BG detected pain as an initial symptom of the disease in $5.43 \%$ of the patients.

$6.2 \%$ of the participants required further clarification with regard to the words "abnormal" and "involuntary" in item 5. In some cases, additional explanations were required for other items. This allows us to propose the use of the questionnaire and scale in the presence of a medical specialist who is trained to recognize the specific taxonomy of pain in PD.

Due to the lack of consensus on the diagnosis and therapy, pain in PD is still insufficiently managed in routine clinical practice. In the present study, this is reflected by means of the finding that $79.63 \%$ of the participants reported one or more types of pain, but only $10.85 \%$ received medications for pain relief.

The current study has some limitations: The main one is the small sample size for the test-retest reliability. Only those patients that came to a follow-up visit two weeks after the first assessment and could be examined by the same senior neurologist were included. This could be a potential source of bias. However, the results are in line with previous studies. Second, the number of patients with advanced disease (modified H\&Y stage 4 and 5) is underrepresented, mainly due to the exclusion criteria. Third, the methodological design of the study is not a case-control. Therefore, no control group was included. All assessments are made in on medication phase.

\section{Conclusions}

Pain is a common, disabling and influencing the patient's QoL non-motor symptom in PD, but still a challenge for the clinicians. Standardized outcome measurements would help developing consensus on pain management in PD. As many other tools, KPPS was provided in English language and tailored to suit the specifics of the Anglo-Saxon culture. Translation and application in another language requires linguistic and cultural adaptation and a statistical validation. In this study, the KPPS was translated, cross-culturally adapted, and validated into Bulgarian language for the first time. Results of the present study demonstrate that the KPPS-BG has good reliability and validity. The Cronbach's $\alpha$ 0,75 of total scale indicate good level of internal consistency. Our results showed that KPPS-BG constitutes a useful pain assessment tool evaluating the frequency and severity of pain associated with PD. It can also be useful for monitoring the therapeutic management of PD-related pain. This study supports the use of the KPPS as an intercultural comparable assessment tool.

\section{Abbreviations}

KPPS: King's Parkinson's Disease Pain Scale KPPS; KPPS-BG: Bulgarian version of the King's Parkinson's Disease Pain Scale; KPPQ: King's Parkinson's Disease Pain Questionnaire; PD: Parkinson's disease; QoL: Quality of life; NMS: Nonmotor symptom; MMSE: Mini-Mental State Examination; H\&Y: Hoehn and Yahr; MDS-UPDRS: Movement Disorders Society Unified Parkinson's Disease Rating Scale; LEDD: Levodopa equivalent daily dose; ICC: Intraclass correlation coefficient; Cl: Confidence interval; TD: Tremor-dominant; PIGD: Postural Instability Gait Disorder; SD: Standard deviation; PLM: Periodic limb movements; RLS: Restless legs syndrome

\section{Acknowledgements \\ Not applicable.}

\section{Authors' contributions}

GS-P reviewed the literature, data collection, analyzed and interpreted the data, wrote the original draft. IM researched data for the article, contributed to the concept and design of the work, reviewed the manuscript. KS performed the statistical analysis and created figures, interpreted the data, reviewed, and edited the manuscript before submission. All authors read and approved the final version of the manuscript.

\section{Funding}

Not applicable.

\section{Availability of data and materials}

The datasets used and analyzed during the current study are available from the corresponding author on reasonable request.

\section{Declarations}

Ethics approval and consent to participate

The study protocol was approved by the Ethics Committee of the University Hospital for Active Treatment in Neurology and Psychiatry "St Naum", Sofia. All participants provided written informed consent.

\section{Consent for publication}

Not applicable.

\section{Competing interests}

The authors declare that they have no competing interests.

\section{Author details}

${ }^{1}$ St. Naum Hospital of Neurology and Psychiatry, Medical University, 1, Louben Roussev str., 1113 Sofia, Bulgaria. ${ }^{2}$ Institute of Neurobiology, Bulgarian Academy of Sciences, Sofia, Bulgaria.

Received: 2 April 2021 Accepted: 8 September 2021

Published online: 15 September 2021

\section{References}

1. Parkinson J. An essay on the shaking palsy. 1817. J Neuropsychiatry Clin Neurosci. 2002;14:223-36.

2. Ha AD, Jankovic J. Pain in Parkinson's disease. Mov Disord. 2012;27:485-91.

3. Barone P, Antonini A, Colosimo C. et al. The PRIAMO study: A multicenter assessment of nonmotor symptoms and their impact on quality of life in Parkinson's disease. Mov Disord. 2009;24:1641-9.

4. Martinez-Martin P, Manuel Rojo-Abuin J, Rizos A. et al. Distribution and impact on quality of life of the pain modalities assessed by the King's Parkinson's disease pain scale. Npj Park Dis. 2017;3:1-6.

5. Politis M, Wu K, Molloy S. et al. Parkinson's disease symptoms: The patient's perspective. Mov Disord. 2010;25:1646-51.

6. O'Sullivan SS, Williams DR, Gallagher DA. et al. Nonmotor symptoms as presenting complaints in Parkinson's disease: A clinicopathological study. Mov Disord. 2008;23:101-6.

7. Broen MPG, Braaksma MM, Patijn J. et al. Prevalence of pain in Parkinson's disease: A systematic review using the modified QUADAS tool. Mov Disord. 2012;27:480-4.

8. Juniper M, Le TK, Mladsi D. The epidemiology, economic burden, and pharmacological treatment of chronic low back pain in France, Germany, 
Italy, Spain and the UK: a literature-based review. Expert Opin Pharmacother. 2009;10:2581-92.

9. Nègre-Pagès L, Regragui W, Bouhassira D. et al. Chronic pain in Parkinson's disease: The cross-sectional French DoPaMiP survey. Mov Disord. 2008;23: $1361-9$

10. Ford B. Pain in Parkinson's disease. Mov Disord. 2010;25:98-103.

11. Wasner G, Deuschl G. Pains in Parkinson disease-many syndromes under one umbrella. Nat Rev Neurol. 2012;8:284-94.

12. Perez-Lloret S, Ciampi de Andrade D, Lyons KE, Rodríguez-Blázquez C, Chaudhuri KR, Deuschl G. et al. Rating scales for pain in Parkinson's disease: Critique and recommendations. Mov Disord Clin Pract. 2016;3:527-37.

13. Mylius V, Ciampi de Andrade D, Cury RG, Teepker M, Ehrt U, Eggert KM. et al. Pain in Parkinson's disease: Current concepts and a new diagnostic algorithm. Mov Disord Clin Pract. 2015;2:357-64.

14. Chaudhuri KR, Rizos A, Trenkwalder C. et al. King's Parkinson's disease pain scale, the first scale for pain in PD: An international validation: King's PD Pain Scale Validation. Mov Disord. 2015;30:1623-31.

15. Rodríguez-Violante M, Alvarado-Bolaños A, Cervantes-Arriaga A. et al. Clinical Determinants of Parkinson's Disease-associated Pain Using the King's Parkinson's Disease Pain Scale. Mov Disord Clin Pract. 2017;4:545-51.

16. Silverdale MA, Kobylecki C, Kass-lliyya L. et al. A detailed clinical study of pain in 1957 participants with early/moderate Parkinson's disease. Parkinsonism Relat Disord. 2018:56:27-32.

17. Mattos DC de, Filho NAM, Pedron CA, et al. Pain Characteristics and Their Relationship With Motor Dysfunction in Individuals With Parkinson Disease-A Cross-Sectional Study. Pain Pract. 2019;19:732-9.

18. Rascol O, Zesiewicz T, Chaudhuri KR. et al. A Randomized Controlled Exploratory Pilot Study to Evaluate the Effect of Rotigotine Transdermal Patch on Parkinson's Disease-Associated Chronic Pain. J Clin Pharmacol. 2016:56:852-61.

19. Trenkwalder C, Chaudhuri KR, Martinez-Martin P. et al. Prolonged-release oxycodone-naloxone for treatment of severe pain in patients with Parkinson's disease (PANDA): a double-blind, randomised, placebocontrolled trial. Lancet Neurol. 2015;14:1161-70.

20. DiMarzio M, Pilitsis JG, Gee L, et al. King's Parkinson's Disease Pain Scale for Assessment of Pain Relief Following Deep Brain Stimulation for Parkinson's Disease. Neuromodulation. 2018;21(6):617-22.

21. Jost WH, Rizos A, Odin P. et al. King's Parkinson's Disease Pain Scale: Interkulturelle Adaption in deutscher Sprache. Nervenarzt. 2018;89:178-83.

22. Soyuer F, Gültekin M, Cankurtaran F. et al. Reliability and validity of the Turkish version of king's Parkinson's disease pain scale. Neurol Sci Neurophysiol. 2020;37:57.

23. Behari M, Srivastava A, Achtani R, et al. Pain Assessment in Indian Parkinson's Disease Patients Using King's Parkinson's Disease Pain Scale. Ann Indian Acad Neurol. 2020;23(6):774-80.

24. Taghizadeh G, Joghataei MT, Goudarzi S, et al. King's Parkinson's disease pain scale cut-off points for detection of pain severity levels: A reliability and validity study. Neurosci Lett. 2021;6:135620.

25. Hughes AJ, Daniel SE, Kilford L, et al. Accuracy of clinical diagnosis of idiopathic Parkinson's disease. A clinico-pathological study of 100 cases. J Neurol Neurosurg Psychiatry. 1992;55:181-4.

26. Folstein MF, Robins LN, Helzer JE. The Mini-Mental State Examination. Arch Gen Psychiatry. 1983:40:812-2.

27. Goetz CG, Poewe W, Rascol O. et al. Movement Disorder Society Task Force report on the Hoehn and Yahr staging scale: Status and recommendations The Movement Disorder Society Task Force on rating scales for Parkinson's disease. Mov Disord. 2004;19:1020-8.

28. Goetz CG, Tilley BC, Shaftman SR. et al. Movement Disorder Societysponsored revision of the Unified Parkinson's Disease Rating Scale (MDSUPDRS): scale presentation and clinimetric testing results. Mov Disord Off J Mov Disord Soc. 2008:23:2129-70.

29. Stebbins GT, Goetz CG, Burn DJ, et al. How to identify tremor dominant and postural instability/gait difficulty groups with the movement disorder society unified Parkinson's disease rating scale: comparison with the unified Parkinson's disease rating scale. Mov Disord. 2013;28(5):668-70.

30. Tomlinson CL, Stowe R, Patel S. et al. Systematic review of levodopa dose equivalency reporting in Parkinson's disease: Systematic Review of LED Reporting in PD. Mov Disord. 2010;25:2649-53.

31. Martinez-Martin P, Rizos AM, Wetmore J. et al. First comprehensive tool for screening pain in Parkinson's disease: The King's Parkinson's Disease Pain Questionnaire. Eur J Neurol. 2018;25:1255-61.
32. Park MS, Kang KJ, Jang SJ, et al. Evaluating test-retest reliability in patientreported outcome measures for older people: A systematic review. Int J Nurs Stud. 2018;79:58-69.

33. Parmenter $\mathrm{K}$, Wardle J. Evaluation and Design of Nutrition Knowledge Measures. J Nutr Educ. 2000;32:269-77.

34. Nunnally JC. Psychometric theory 3th ed. New York: Basic Books; 1994. 265 p.

35. Shrout PE, Fleiss JL. Intraclass correlations: uses in assessing rater reliability. Psychol Bull. 1979;86(2):420-8.

36. Slick DJ. Psychometrics in neuropsychological assessment. In: Strauss E, Sherman $E(E d s$.$) . A compendium of neuropsychological tests:$ Administration, norms, and commentary. New York: Oxford University Press: 2006. (pp. 3-43). In.

37. Callister LC. Cultural Influences on Pain Perceptions and Behaviors. Home Health Care Manag Pract. 2003;15:207-11.

38. Buhmann C, Wrobel N, Grashorn W. et al. Pain in Parkinson disease: a crosssectional survey of its prevalence, specifics, and therapy. J Neurol. 2017;264: 758-69.

\section{Publisher's Note}

Springer Nature remains neutral with regard to jurisdictional claims in published maps and institutional affiliations.

Ready to submit your research? Choose BMC and benefit from:

- fast, convenient online submission

- thorough peer review by experienced researchers in your field

- rapid publication on acceptance

- support for research data, including large and complex data types

- gold Open Access which fosters wider collaboration and increased citations

- maximum visibility for your research: over $100 \mathrm{M}$ website views per year

At BMC, research is always in progress.

Learn more biomedcentral.com/submissions 